\title{
УСЛОВИЯ СЕЛЕКТИВНОГО И СОВМЕСТНОГО ИЗВЛЕЧЕНИЯ ИОНОВ ЖЕЛЕЗА И МЕДИ ИЗ НИКЕЛЕВОГО ЭЛЕКТРОЛИТА ЭКСТРАКЦИЕЙ СМЕСЬЮ ОЛЕИНОВОЙ КИСЛОТЫ И ТРИЭТАНОЛАМИНА В КЕРОСИНЕ
} Н.Б. Кокоева", Н.Т. Кисиев ${ }^{* *}$, Л.А. Воропанова ${ }^{* * *}$

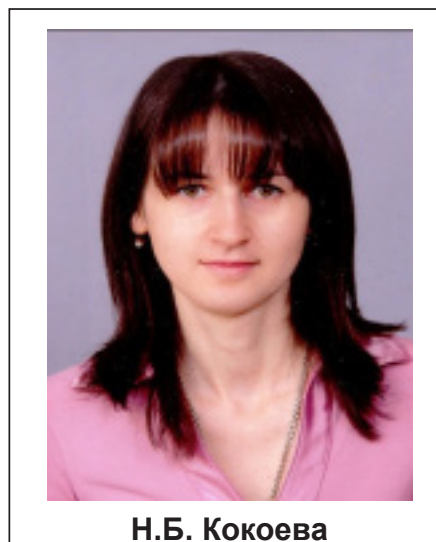

Н.Б. Кокоева

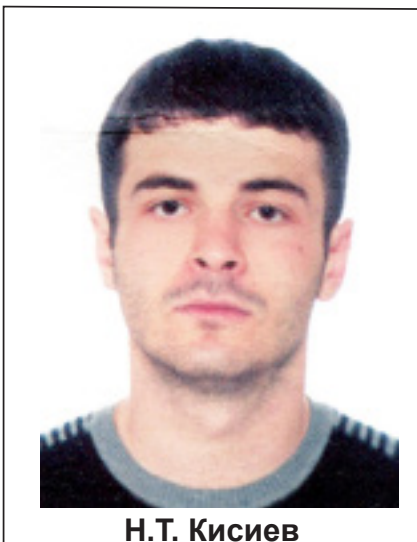

Н.Т. Кисиев

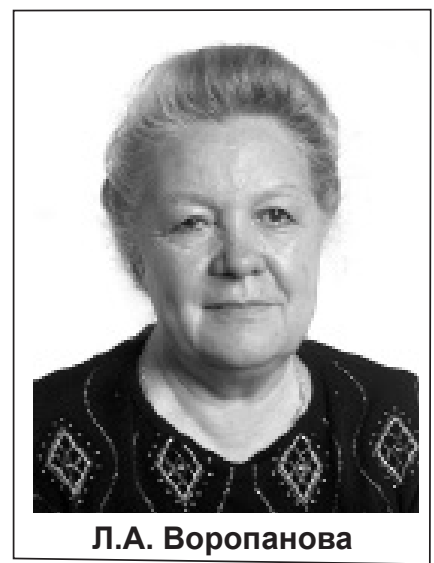

Л.А. Воропанова

Аннотация. Определены оптимальные условия селективного и совместного извлечения примесей меди и железа из никелевого электролита экстракцией смесью олеиновой кислоты и триэтаноламина в керосине. ключевые слова: селективное извлечение, никелевый электролит, олеиновая кислота, триэтаноламин.

Для получения качественного никеля необходимо, чтобы содержание примесей $\mathrm{Cu}, \mathrm{Fe}$ и др. в электролите не превышало оптимальных концентраций.

При растворении никелевого анода большинство примесей переходит в раствор, создавая концентрации, во много раз превышающие оптимальные. Поэтому для получения катодного никеля требуемого качества необходимо очистка никелевого электролита от металлов-примесей [1-4].

Ионы меди из никелевого электролита обычно удаляют методом цементации более электроотрицательным металлом - никелем. Для этой цели используют никелевый порошок. Очистка электролита от железа проводится путем окисления хлором для перевода железа в трехвалентное состояние и последующего осаждения в виде основных солей переменного состава, нейтрализацию кислоты гидролиза осуществляют карбонатом никеля [5-10].

Целью работы является поиск оптимальных условий (величина $\mathrm{pH}$ и объемное соотношение водной В и органической О фаз В : О) селективного и совместного извлечения железа и меди из никелевого электролита экстракцией. Состав электролита, г/дм ${ }^{3}:$ 0,5 - 0,89 Fe, 1,02 - 1,24 Cu, $63,5-82,7 \mathrm{Ni}$.

В качестве экстрагента использовали смесь олеиновой кислоты и триэтаноламина в керосине в объемном соотношении $12: 6: 82$ соответственно.

Температура исходного раствора $22^{\circ} \mathrm{C}$, величина $\mathrm{pH} 2,2-2,4$.

Экстракцию осуществляли при перемешивании и регулировании постоянной величины pH 30-50 мин, в качестве нейтрализаторов использовали растворы $\mathrm{NaOH}$ и $\mathrm{H}_{2} \mathrm{SO}_{4}$. Нагрев осуществляли до $40-45{ }^{\circ} \mathrm{C}$. Исследованиями установлено, что при комнатной температуре экстракция осуществляется менее эффективно.

На рис. 1 дана схема приборов для проведения экстракции.

Стакан 2 с исходным раствором, содержащим экстрагируемые ионы, и экстрагентом помещали на нагреватель 3 для нагрева смеси до заданной температуры. Для лучшего массообмена содержимое стакана перемешивали мешалкой 1 в течение заданного времени и затем переносили в делительную воронку, где смесь отстаивалась и разделялась на экстракт и рафинат. После отстаивания рафинат, а затем экстракт, через нижнее выходное отверстие делительной воронки сливали в отдельные емкости. Химический анализ изучаемой пробы проводили по стандартным методикам.

Результаты экстракции оценивали извлече-

Кокоева Наталья Борисовна - к. т. Н., старший преподаватель. Северо-Кавказский горно-металлургический институт (Государственный технологический университет), Россия, РСО-А, г. Владикавказ.

" Кисиев Николай Теймуразович - и.о. мастера обжигового иеха Никелевого завода ОАО «ГМК «Норильский никель».

Воропанова Лидия Алексеевна - д. т. н., профрессор, Северо-Кавказский горно-металлургический институт (Государственный технологический университет, Россия, PCO-A, г. Владикавказ (lidia_metalllidia_metall@mail.ru). 
нием металлов в экстракт $\varepsilon$, \% масс от исходного количества, и коэффрициентом разделения $\beta_{\mathrm{Fe} / \mathrm{Cu}}$ ионов железа (III) и меди (II).

\section{СЕЛЕКТИВНОЕ ИЗВЛЕЧЕНИЕ ИОНОВ ЖЕЛЕЗА}

Условия экстракции: температура $40^{\circ} \mathrm{C}, \quad$ продолжительность экстракции 10-15 мин, $\mathrm{pH}=2,7-4,7, \mathrm{~B}: \mathrm{O}=1-4,5$.

Матрица планирования и результаты эксперимента приведены в табл. 1. Для исследования был выбран линейный план Бокса $\mathrm{B}_{2}$ с числом опытов 8. Независимыми переменными (в безразмерном масштабе) были: $\mathrm{pH}$ раствора $\left(\mathrm{X}_{1}\right)$ и соотношение B:O $\left(\mathrm{X}_{2}\right)$. Ниже приведена связь между безразмерными и размерными масштабами независимых переменных:

$$
\chi_{1}=\frac{p H-3,7}{2,7}, \chi_{2}=\frac{B: O-2,75}{1} .
$$

В результате обработки экспериментальных данных получены адекватные математические модели извлечения железа и коэффрициента разделения в кодовом масштабе:

- извлечение железа в экстракт:

$$
\begin{aligned}
& \varepsilon_{F e}=61,811-11,444 \chi_{1}+6,133 \chi_{2}+3,205 \chi_{1}^{2}+1 \\
& +0,496 \chi_{2}^{2}-1,003 \chi_{1} \chi_{2}(1) \\
& \left(S_{a d}^{2}=2,133 ; \mathrm{F}=71,093 ; \mathrm{F}_{0,05 ; 7 ; 2}=19,353\right) ;
\end{aligned}
$$

1 - мешалка

2 - стакан

3 - нагреватель

4 - делительная воронка

Puc. 1. Схема приборов для проведения экстракции

тракт оказывает величина $\mathrm{pH}$, затем - отношение В: О.

По полученным математическим моделям проведена оптимизация (табл. 2) с определением значений независимых переменных в кодовом масштабе, соответствующих наибольшему извлечению железа.

Условному оптимуму соответствуют следующие значения независимых переменных в процессе экстракции никелевого электролита: $(\mathrm{pH})$ $\mathrm{X}_{1}=-1(2,7)$ и отношение $\left(\mathrm{B}:\right.$ O) $\mathrm{X}_{2}=+1(4,5)$.

Этим условиям соответствует опыт 3 табл. 1 , в котором получены следующие значения зависимых переменных: $\varepsilon_{\mathrm{Fe}}=80,46 \%, \varepsilon_{\mathrm{Cu}}=3,56 \%$ и $\beta_{\mathrm{Fel} / \mathrm{Cu}}=114,31$.

$\beta_{\mathrm{Fe} / \mathrm{Cu}}=1,393 \cdot 10^{3}-510,719 \chi_{1}+61,551 \chi_{2}+47,637 \chi_{1}^{2}$

$$
+8,651 \chi_{2}^{2}-16,49 \chi_{1} \chi_{2}
$$

$$
\left(\mathrm{F}=72,448 ; \mathrm{F}_{0,05 ; 7 ; 2}=19,353\right) ;
$$

где $\varepsilon_{\text {мe }}-$ извлечение металла в раствор, \%; $\beta_{F е / C u}-$ коэфрфициент разделения;

$\chi_{1}-\mathrm{pH}$ раствора в безразмерном масштабе;

$\chi_{2}$ - соотношение В:О в безразмерном масштабе;

$S_{a d}^{2}$ - дисперсия адекватности;

$\mathrm{F} \quad$ - экспериментальное значение F-статистики;

$\mathrm{F}_{0,05 ; \mathrm{N}-1 ; \mathrm{N}-\mathrm{k}}-$ табличное значение критерия Фишера.

Так как получены низкие показатели извлечения меди, математическая обработка экспериментальных данных не производилась.

В связи с тем, что для уравнений (1-2) $\mathrm{F}>\mathrm{F}_{0,05 ; \mathrm{N}-1 ; \mathrm{N}-\mathrm{k}}$, они признаны адекватными экспериментальным данным с уровнем значимости 0,05.

Из уравнения (1-2) следует, что самое сильное влияние на извлечение железа в экс-
На puc. 2 по данным табл. 1 получены результаты селективного извлечения железа (III) в экстракт из никелевого электролита смесью олеиновой кислоты и триэтаноламина в керосине в зависимости от величины $\mathrm{pH}$ и соотношения В : О, температура $40^{\circ} \mathrm{C}$, продолжительность экстракции 10-15 мин:

\begin{tabular}{|c|c|c|c|c|c|c|c|}
\hline \multirow{2}{*}{$\begin{array}{l}\text { № } \\
\Pi / \Pi\end{array}$} & \multicolumn{2}{|c|}{$\begin{array}{c}\text { Кодовый } \\
\text { масштаб }\end{array}$} & \multicolumn{2}{|c|}{$\begin{array}{c}\text { Натуральный } \\
\text { масштаб }\end{array}$} & \multicolumn{2}{|c|}{$\begin{array}{c}\text { Извлечено в } \\
\text { экстракт, \% } \\
\end{array}$} & \multirow{2}{*}{$\beta_{\mathrm{Fe} / \mathrm{Cu}}$} \\
\hline & $\mathrm{X}_{1}$ & $\mathrm{X}_{2}$ & $\mathrm{pH}$ & $\mathrm{B}: \mathrm{O}$ & $\mathrm{Cu}$ & $\mathrm{Fe}$ & \\
\hline 1 & -1 & -1 & 2,7 & 1 & 9,06 & 58,64 & 17,8 \\
\hline 2 & 1 & -1 & 4,7 & 1 & 20,65 & 80,02 & 104,88 \\
\hline 3 & -1 & 1 & 2,7 & 4,5 & 3,56 & 80,46 & 114,31 \\
\hline 4 & 1 & 1 & 4,7 & 4,5 & 27,9 & 94,82 & 85,96 \\
\hline 5 & -1 & 0 & 2,7 & 2,75 & 6,23 & 66,29 & 36,86 \\
\hline 6 & 1 & 0 & 4,7 & 2,75 & 26,84 & 87,64 & 71,63 \\
\hline 7 & 0 & -1 & 3,7 & 1 & 8,62 & 66,54 & 18,4 \\
\hline 8 & 0 & 1 & 3,7 & 4,5 & 9,82 & 84,02 & 47,8 \\
\hline
\end{tabular}

$$
\text { a - извлечение железа } \varepsilon_{\mathrm{Fe}} \text {, }
$$

Матрица планирования и результаты эксперимента экстракции ионов железа и меди из никелевого электролита смесью олеиновой кислоты и триэтаноламина в керосине 
б - коэфффициент разделения $\beta_{\mathrm{Fe} / \mathrm{Cu}}$.

\section{СОВМЕСТНОЕ ИЗВЛЕЧЕНИЕ ИОНОВ ЖЕЛЕЗА И МЕДИ}

Условия экстракции: температуpa $40{ }^{\circ} \mathrm{C}$, продолжительность экстракции 50 мин., $\mathrm{pH}=5-7, \mathrm{~B}: \mathrm{O}=$ 1- 4,5.

Матрица планирования и результаты эксперимента приведены в табл. 3. Для исследования был выбран линейный план Бокса $\mathrm{B}_{2}$ с числом опытов 8. Независимыми переменными (в безразмерном масштабе) были: $\mathrm{pH}$ раствора $\left(\mathrm{X}_{1}\right)$ и соотношение В : O $\left(\mathrm{X}_{2}\right)$. Ниже приведена связь между безразмерными и размерными масштабами независимых переменных:

$$
\chi_{1}=\frac{p H-6}{5}, \chi_{2}=\frac{B: O-2,75}{1} .
$$

В результате обработки экспериментальных данных получены адекватные математические модели извлечений металлов в кодовом масштабе:

- извлечение меди в экстракт:

$\varepsilon_{C u}=77,206-2,396 \chi_{1}+7,553 \chi_{2}+0,525 \chi_{1}^{2}-$

$-1,069 \chi_{2}^{2}-0,286 \chi_{1} \chi_{2} ;$

$\left(S_{a d}^{2}=0,178 ; \mathrm{F}=62,646 ; \mathrm{F}_{0,05 ; 7 ; 2}=19,353\right)$

$\varepsilon_{F e}=77,11-1,195 \chi_{1}+13,488 \chi_{2}+0,21 \chi_{1}^{2}-$

$-1,918 \chi_{2}^{2}-0,12 \chi_{1} \chi_{2}$

$\left(S_{a d}^{2}=0,307 ; \mathrm{F}=69,917 ; \mathrm{F}_{0,05 ; 7 ; 2}=19,353\right)$,

где $\varepsilon_{\text {мe }}$ - извлечение металла в раствор, \%;

$\chi_{1}-\mathrm{pH}$ раствора в безразмерном масштабе;

$\chi_{2}$ - соотношение В : О в безразмерном масштабе;

$S_{a d}^{2}$ - дисперсия адекватности;

$\mathrm{F}$ - экспериментальное значение F-статистики;

$\mathrm{F}_{0,05 ; \mathrm{N}-1 ; \mathrm{N}-\mathrm{k}}$ - табличное значение критерия Фишера.

В связи с тем, что для уравнений (3-4) $\mathrm{F}>\mathrm{F}_{0,05 ; \mathrm{N}-1 ; \mathrm{N}-\mathrm{k}}$, Они признаны адекватными экспериментальным данным с уровнем значимости 0,05.

Из уравнений (3-4) следует, что самое сильное влияние на извлечение меди и железа в экстракт ока-
Таблица 2

Результаты оптимизации по моделям (1-2)

\begin{tabular}{|c|c|c|c|}
\hline \multirow{2}{*}{$\begin{array}{c}\text { Функция } \\
\text { оптимизации }\end{array}$} & \multicolumn{2}{|c|}{$\begin{array}{c}\text { Условия } \\
\text { оптимумов }\end{array}$} & $\begin{array}{c}\text { Значения } \\
\text { функций } \\
\text { отклика }\end{array}$ \\
\cline { 2 - 3 } & $\mathrm{X}_{1}$ & $\mathrm{X}_{2}$ & 84,092 \\
\hline$\varepsilon_{\mathrm{Fe}}$ & -1 & +1 & 2038 \\
\hline$\beta_{F e / C u}$ & -1 & +1 & \\
\hline
\end{tabular}

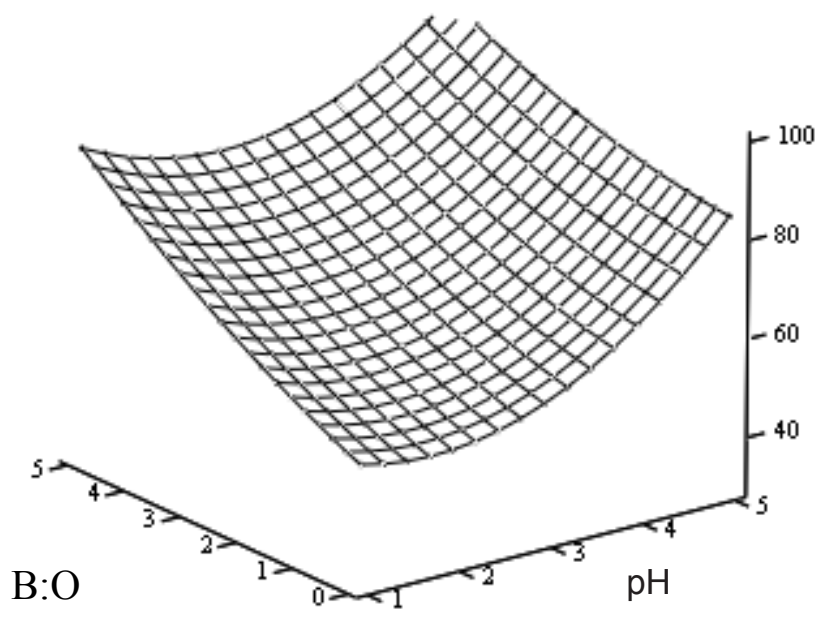

$\varepsilon_{\mathrm{Fe}}$

a)

$\beta_{\mathrm{Fe} / \mathrm{Cu}}$

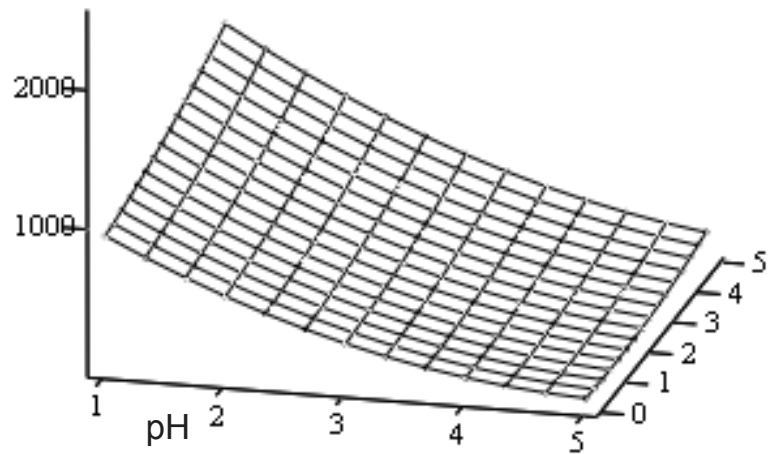

Puc. 2. Результаты селективного извлечения железа (III) в экстракт из никелевого электролита смесью олеиновой кислоты и триэтаноламина в керосине в зависимости от величины рН и соотношения В : О, температура 40

${ }^{\circ} \mathrm{C}$, продолжительность экстракции 10-15 мин: a - извлечение железа $\varepsilon_{F e}$, б - коэфрфициент разделения $\beta_{\mathrm{Fe} / \mathrm{Cu}}$

Таблица 3

Матрица планирования и результаты эксперимента экстракции ионов железа и меди из никелевого электролита смесью олеиновой кислоты и триэтаноламина в керосине

\begin{tabular}{|c|c|c|c|c|c|c|}
\hline \multirow{2}{*}{$\begin{array}{c}\text { № } \\
\text { п/п }\end{array}$} & \multicolumn{2}{|c|}{$\begin{array}{c}\text { Кодовый } \\
\text { масштаб }\end{array}$} & \multicolumn{2}{c|}{$\begin{array}{c}\text { Натуральный } \\
\text { масштаб }\end{array}$} & \multicolumn{2}{c|}{$\begin{array}{c}\text { Извлечено в экс- } \\
\text { тракт, \% }\end{array}$} \\
\cline { 2 - 7 } & $\mathrm{X}_{1}$ & $\mathrm{X}_{2}$ & $\mathrm{pH}$ & $\mathrm{B}: \mathrm{O}$ & $\mathrm{Cu}$ & $\mathrm{Fe}$ \\
\hline 1 & -1 & -1 & 5 & 1 & 83,65 & 87,21 \\
\hline 2 & 1 & -1 & 7 & 1 & 90,65 & 90,05 \\
\hline 3 & -1 & 1 & 5 & 4,5 & 84,25 & 95,25 \\
\hline 4 & 1 & 1 & 7 & 4,5 & 89,25 & 97,25 \\
\hline 5 & -1 & 0 & 5 & 2,75 & 86,87 & 97,75 \\
\hline 6 & 1 & 0 & 7 & 2,75 & 93,58 & 98,88 \\
\hline 7 & 0 & -1 & 6 & 1 & 86,25 & 88,21 \\
\hline 8 & 0 & 1 & 6 & 4,5 & 86,60 & 96,25 \\
\hline
\end{tabular}


зывает соотношение В : О, затем - величина $\mathrm{pH}$.

По полученным математическим моделям проведена оптимизация (табл. 4) с определением значений независимых переменных в кодовом масштабе, соответствующих наибольшему извлечению меди и железа. Как видно, оптимальные условия экстракции совпадают по $\mathrm{X}_{1}$ и по $\mathrm{X}_{2}$.

Таким образом, условному оптимуму соответствуют следующие значения независимых переменных в процессе экстракции никелевого электролита: $(\mathrm{pH})$ $\mathrm{X}_{1}=-1(5)$ и $(\mathrm{B}: \mathrm{O}) \mathrm{X}_{2}=+1(4,5)$.

Этим условиям соответствует опыт 3 (см. табл. 3), в котором получены следующие значения зависимых переменных: $\varepsilon_{\mathrm{Cu}}=84,25 \%, \varepsilon_{\mathrm{Fe}}=95,25 \%$.

На рис. 3 по данным табл. 3 показана зависимость совместного извлечения железа $\varepsilon_{\mathrm{Fe}}\left(\right.$ (а) и меди $\varepsilon_{\mathrm{Cu}}$ (б) в экстракт из никелевого электролита от величины $\mathrm{pH}$ и соотношения В : О экстракцией смесью олеиновой кислоты и триэтаноламина в керосине, температура $40{ }^{\circ} \mathrm{C}$, продолжительность экстракции 50 мин.

\section{Выводы}

Экстракцией смесью олеиновой кислоты и триэтаноламина в керосине можно очистить никелевый электролит от примесей железа и меди:

1. Оптимальное значение селективного извлечения железа $\varepsilon_{\mathrm{Fe}}=80,46 \%$, $\left(\varepsilon_{\mathrm{Cu}}=3,56 \%\right)$ и $\beta_{\mathrm{Fe} / \mathrm{Cu}}=114,31$ возможно при $\mathrm{pH}=2,7$ и $\mathrm{B}: \mathrm{O}=4,5$;

2. Оптимальное значение совместного извлечения железа (III) $\varepsilon_{\mathrm{Fe}}=95,25 \%$ и меди (II) $\varepsilon_{\text {си }}=84,25 \%$ возможно при $\mathrm{pH}$ $=5$ и $\mathrm{B}: \mathrm{O}=4,5$.

Результаты оптимизации по моделям (3-4)

Таблица 4

\begin{tabular}{|c|c|c|c|}
\hline \multirow{2}{*}{$\begin{array}{c}\text { Функция } \\
\text { оптимизации }\end{array}$} & \multicolumn{2}{|c|}{$\begin{array}{c}\text { Условия } \\
\text { оптимумов }\end{array}$} & \multirow{2}{*}{$\begin{array}{c}\text { Значения } \\
\text { функций } \\
\text { отклика }\end{array}$} \\
\cline { 2 - 3 } & $\mathrm{X}_{1}$ & $\mathrm{X}_{2}$ & 90,205 \\
\hline$\varepsilon_{\mathrm{Fe}}$ & -1 & +1 & 86,897 \\
\hline$\varepsilon_{\mathrm{Cu}}$ & -1 & +1 & \\
\hline
\end{tabular}

a)

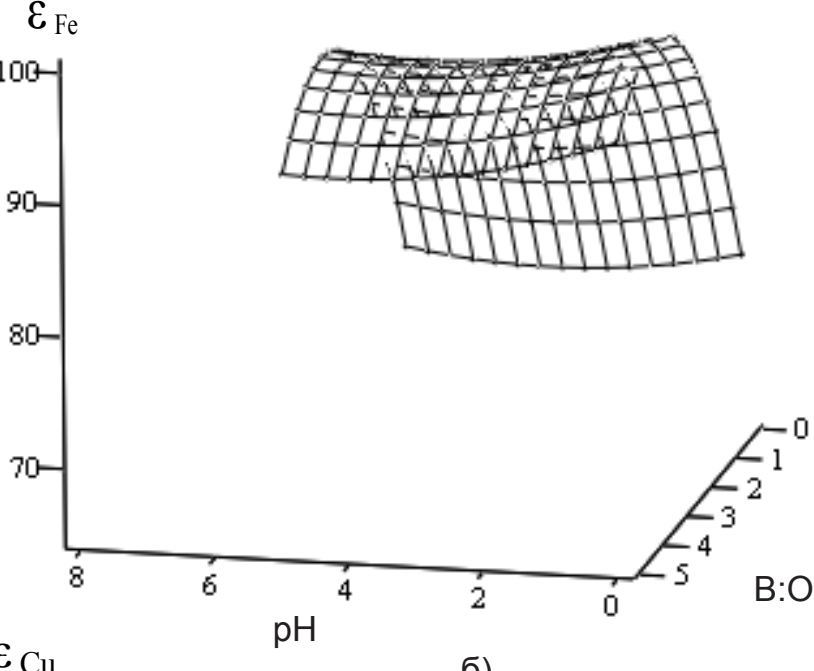

б)

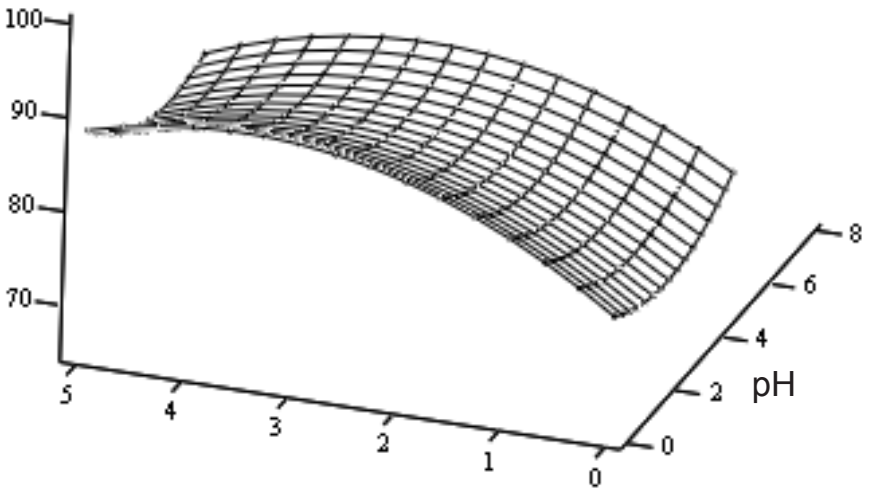

$\mathrm{B}: \mathrm{O}$

Puc. 3. Зависимость совместного извлечения железа $\varepsilon_{\mathrm{Fe}}$ (a) и меди $\varepsilon_{\mathrm{cu}}$ (б) в экстракт из никелевого электролита от величины рН и соотношения В : О экстракцией смесью олеиновой кислоты и триэтаноламина в керосине, температура $40{ }^{\circ} \mathrm{C}$, продолжительность экстракции 50 мин.

Исследование выполнено при фринансовой поддержке РФФИ и Министерства образования и науки Республики Северная Осетия-Алания в рамках научного проекта № 17-48-150696|17

\section{ЛИТЕРАТУРА}

1. Худяков И.Ф., Кляйн С.Э., Агеев Н.Г. Металлургия меди, никеля, сопутствующих элементов и проектирование цехов. - М.: Металлургия, 1993. 432 с.

2. Резник И.Д., Соболь С.И., Худяков В.М. Кобальт. - М. Машиностроение. ч. 2, 1995. С. 351-397.
3. Шиврин Г.Н., Головицкая Т.А., Илюшин С.А., Колманов A.А. Проблемы электролиза меди и никеля. - Рязань: НП «Голос губернии», 2011. 352 c.

4. Набойченко С.С., Ни Л.П., Шеерсон Я.М., Чугаев Л.В. Автоклавная гидрометаллургия цветных металлов. - Ека- 
теринбург: Изд-во УГТУ-УПИ, 2002. 940 с.

5. Воропанова Л.А. Обезвреживание стоков, содержащих ионы цветных металлов, путем экстракции их смесью олеиновой кислоты и триэтаноламина // Изв. ВУЗов, Цветная металлураия, № 5, 2001. С. 32-38.

6. Воропанова Л.А., Кисиев Н.Т. Очистка никелевого электролита от примесей железа (III) и меди (II) экстракцией смесью олеиновой кислоты и триэтаноламина / Записки горного института. T. 214, 2015. C. 28-33.

7. Воропанова Л.А., Кисиев Н.Т. Гагиева З.А. Экстракция ионов железа и меди из водных растворов смесью олеи новой кислоты и триэтаноламина в керосине / Вестник ДонНТУ. Специальный выпуск «Металлургические процессы и оборудование». 2016. № 4(4). С. 10-14.

8. Патент РФ 2591915, C22B 3/40, C22B 15/00, заявка
2015105130/02, приоритет 16.02.2015, опубл. 20.07.2016 БИ № 20. Воропанова Л.А., Кисиев Н.Т., Гагиева З.А. Способ экстракции ионов железа и меди из водных растворов смесью олеиновой кислоты и триэтаноламина в керосине. 9. Патент РФ 2604286, C25D 21/18, заявка 2015127592, приоритет 08.07.2015, опубл. 10.12.2016 БИ № 34. Воропанова Л.А., Кисиев Н.Т., Гагиева З.А. Способ очистки никелевого электролита от примесей железа (III) и меди (II) экстракцией смесью олеиновой кислоты и триэтаноламина.

10. Патент РФ 2604289, С22B 3/26, C22B 23/00, С22B 15/00, заявка 2015127591, приоритет 08.07.2015, опубл. 10.12.2016 БИ № 34. Воропанова Л.А., Кисиев Н.Т., Гагиева 3.А. Способ очистки никелевого электролита от примесей железа (III), кобальта (III) и меди (II) экстракцией.

\section{CONDITIONS FOR SELECTIVE AND JOINT EXTRACTION OF IRON AND COPPER IONS FROM NICKEL ELECTROLYTE BY EXTRACTION WITH A MIXTURE OF OLEIC ACID AND TRIETHANOLA-MINE IN KEROSENE \\ N.B. Kokoeva ${ }^{1}$, N.T. Kisiev ${ }^{2}$, L.A. Voropanova ${ }^{3}$}

${ }^{1}$ North Caucasian Institute of Mining and Metallurgy (State Technological University), NCIMM (STU) 2 Noril'skii Nikel' GMK OAO.

${ }^{3}$ Dr, professor. North Caucasian Institute of Mining and Metallurgy (State Technological University), NCIMM (STU) (lidia metallidia metall@mail.ru).

Abstract. Optimum conditions for selective and collaborative extraction of copper and iron impurities from nickel electrolyte by extraction with a mixture of oleic acid and triethanolamine in kerosene were determined. Keywords: selective extraction, nickel electrolyte, oleic acid, triethanolamine.

\section{REFERENCES}

1. Khudyakov I.F., Klyayn S.E., Ageev N.G. Metallurgiya medi, nikelya, soputstvuyushchikh elementov proektirovanie tsekhov. - M.: Metallurgiya, 1993. 432 s.

2. Reznik I.D., Sobol' S.I., Khudyakov V.M. Kobal't. - M.: Mashinostroenie. ch. 2, 1995. S. 351-397.

3. Shivrin G.N., Golovitskaya T.A., Ilyushin S.A., Kolmanov A.A. Problemy elektroliza medi i nikelya. - Ryazan': $N P$ «Golos gubernii», 2011. 352 s.

4. Naboychenko S.S., Ni L.P., Sheerson Ya.M., Chugaev L.V. Avtoklavnaya gidrometallurgiya tsvetnykh metallov. - Ekaterinburg: Izd-vo UGTU-UPI, 2002. 940 s.

5. Voropanova L.A. Obezvrezhivanie stokov, soderzhashchikh iony tsvetnykh metallov, putem ekstraktsii ikh smes'yu oleinovoy kisloty i trietanolamina // Izv. VUZov, Tsvetnaya metallurgiya, № 5, 2001. S. 32-38.

6. Voropanova L.A., Kisiev N.T. Ochistka nikelevogo elektrolita ot primesey zheleza (III) i medi (II) ekstraktsiey smes'yu oleinovoy kisloty i trietanolamina / Zapiski gornogo instituta. T. 214, 2015. S. 28-33.

7. Voropanova L.A., Kisiev N.T. Gagieva Z.A. Ekstraktsiya ionov zheleza i medi iz vodnykh rastvorov smes'yu oleinovoy kisloty $i$ trietanola-mina v kerosine / Vestnik DonNTU. Spetsial'nyy vypusk «Metallurgicheskie protsessy i oborudovanie». 2016. № 4(4). S. 10-14.

8. Patent RF 2591915, C22B 3/40, C22B 15/00, zayavka 2015105130/02, prioritet 16.02.2015, opubl. 20.07.2016 BI № 20. Voropanova L.A., Kisiev N.T., Gagieva Z.A. Sposob ekstraktsii ionov zheleza i medi iz vodnykh rastvorov smes'yu oleinovoy kisloty i trietanolamina $v$ kerosine.

9. Patent RF 2604286, C25D 21/18, zayavka 2015127592, prioritet 08.07.2015, opubl. 10.12.2016 Bl № 34 Voropanova L.A., Kisiev N.T., Gagieva Z.A. Sposob ochistki nikelevogo elektrolita ot primesey zheleza (III) $i$ medi (II) ekstraktsiey cmes'yu oleinovoy kisloty i trietanolamina.

10. Patent RF 2604289, C22B 3/26, C22B 23/00, C22B 15/00, zayavka 2015127591, prioritet 08.07.2015, opubl. 10.12.2016 BI № 34. Voropanova L.A., Kisiev N.T., Gagieva Z.A. Sposob ochistki nikelevogo elektrolita ot primesey zheleza (III), kobal'ta (III) i medi (II) ekstraktsiey.

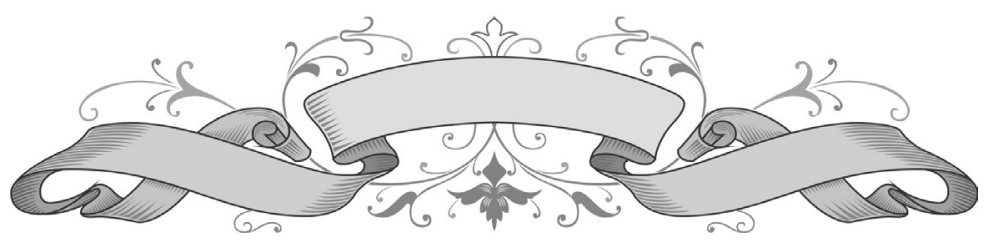

